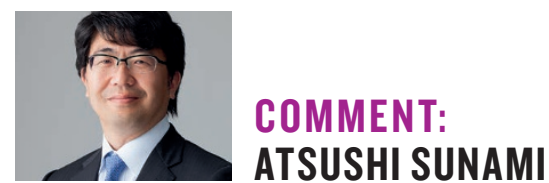

\title{
DRAWING A NEW BOTTOM LINE
}

\author{
'Abenomic' plans to make Japan's universities compete for private funding \\ lie at the heart of reforms to kickstart a struggling sector
}

$\mathrm{S}$ ince the beginning of his term, Prime Minister Shinzo Abe's 'Abenomics' policies have focused on reforming economic institutions that are perceived to hinder innovation.

Despite the strength of the Japanese economy in the latter half of the twentieth century, there is a fear that Japan has fallen behind in the years since.

One avenue was to use the Trans-Pacific Partnership (TPP) trade deal to place Japan firmly on track for globalization. However, with the election of Donald Trump as United States president, the TPP's prospects have been jeopardized and Japan needs to find the momentum for structural reform in other areas. In this respect, the national university system became a top priority.

There are several key objectives to this reform. To unleash the full potential of universities as engines of economic growth, further investment in the system is absolutely necessary. Given Japan's serious budget constraints, however, a significant increase in investment must come from the private sector in the form of joint research or donations.

Like their counterparts in the US, Japanese universities are looking for fundraising opportunities, including efforts to increase endowments. The first objective of the government's university reform is to make these institutions more attractive for private sector investment.

The Cabinet Office is investigating a range of initiatives, including tax incentives for private donations. In addition, universities should gain expertise in fundraising and asset management skills.

The government's second objective is to raise higher education in Japan to world-class levels to ensure the next generation of Japanese students is better prepared to compete in a globalized workforce. Universities should also consider providing mid-career training for the country's existing workforce.

The third objective of the government's reform is to encourage some universities, especially those outside Tokyo, to make a greater contribution to the growth of local economies by training students to work for the small-to-medium sized enterprises (SMEs) that comprise more than $90 \%$ of Japanese companies. A lack of human capital is preventing the growth of SMEs, especially those based on manufacturing and other technologies that are destined for global markets. Local universities are helping SMEs scale up, largely by R\&D investment.

At its core, current discussion around university reforms revolves around making national universities compete for private funding. Reformers within government believe

\section{'THE GOALS ARE BASED ON UNREALISTIC EXPECTATIONS FOR PERFORMANCE WITHOUT PROPER FUNDING.}

\section{UNIVERSITIES BY CATEGORY}

Contributing to local economy Global research focus

Unique teaching/research focus

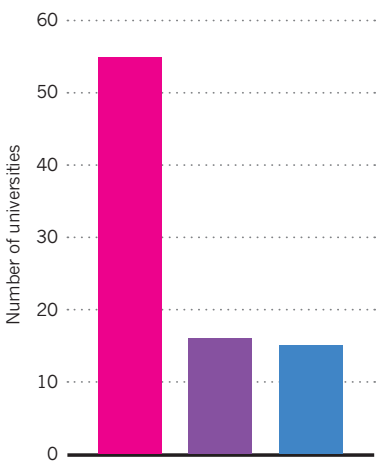

this will make academia more responsive to society, and more financially sustainable.

In 2015, the Ministry of Education, Science and Technology unveiled its plan to meet the government's ambitious objectives. All 86 national universities were asked to classify themselves in one of three categories: research universities that compete globally, universities with unique research or teaching programmes, and universities that contribute to the local economy. While gradually implementing the new measures, funding based on standards relevant to each category started in 2016.

Universities that decide to compete globally will receive privileges, such as deregulation over the management of their assets. In return, these institutions will be evaluated against top universities in the US and Europe. In addition, the ministry will soon select two or three universities as 'special research universities'.

Universities have greeted these reforms with scepticism. Many believe that funding has already been cut so severely that universities no longer have the capacity to reform themselves. Linking the new categories to funding is like operating on a patient whose health condition is too bad to survive the surgery.

While the objectives of the government reforms are understandable, the set goals are based on unrealistic expectations for the performance of Japanese universities without proper funding. It will be some time before we know if the reforms have made Japanese universities more competitive globally, and more responsive to societal needs. Outcomes must be revealed before the public's support for Abenomics runs out.

Without reform, the national university system in Japan will weaken over the coming decade. At least the government and the university sector can agree there is an urgent need for improvement.

Atsushi Sunami is a vice president and professor at the National Graduate Institute for Policy Studies and advisor to the Cabinet Office, Government of Japan. 